\section{Measuring performance}

We agree completely with Dr. Hébert's position that performance measurement should be a major priority. ${ }^{1} \mathrm{He}$ poses the question: "So why do measuring performance and health outcomes elude us?" We suggest an additional reason not mentioned by him measuring quality of care is complex because it is a vague concept that means different things to different people. As a result, different groups derive different indicators. Health systems need to be strategic in moving this agenda forward. We recommend four investments, which we predict will have a large and synergistic impact. One, there should be increased investment in information management technologies that can support performance measurement. Two, there needs to be enhanced training of statisticians, epidemiologists, economists, clinicians and managers to use the clinical data to support informed decision-making. Three, there needs to be increased funding to support thoughtful evaluations of innovations designed to improve quality of care. Four, we need to support collaborations among health system institutions.

\section{Alan J. Forster MD \\ Scientific director, clinical quality and performance management \\ Jack B. Kitts, MD \\ President and CEO \\ The Ottawa Hospital, Ottawa, Ont.}

\section{REFERENCE}

1. Hébert PC. Measuring performance is essential to patient-centred care. CMAJ 2010;182:225.

For the full letter, go to: www.cmaj.ca/cgi/eletters /182/3/225\#292480

DOI: 10.1503/cmaj.110-2040

\section{Patient-centred care}

Our health care system is controlled by the Ministry of Health and the physicians. We hold all the cards. Your editorial "Measuring performance is essential to patient-centred care" emphasizes the importance of a third group: the patients. The most common complaints here in Dufferin County are wait times in doctors' waiting rooms and in the emergency department. Our "fee for service" system rewards the physician but perhaps not always the outcome. So your statement "align funding with performance" cannot be dismissed. Yes, the measurement of performance will not be easy. But it is possible. Our number one priority is to make the start.

\section{Wilfred S. Goodman MD}

Professor emeritus, Faculty of Medicine, University of Toronto

Shelburne, Ont.

\section{REFERENCE}

1. Hébert PC. Measuring performance is essential to patient-centred care. CMAJ 2010;182:225.

For the full letter, go to: www.cmaj.ca/cgi/eletters /182/3/225\#298577

DOI:10.1503/cmaj.110-2052

\section{Rearranging deck chairs}

Attempting to address Canada's clearly financially unsustainable health care system by focusing on centralization or regionalization ${ }^{1}$ is analogous to rearranging the deck chairs on the Titanic. A reality check! Regionalization or centralization has only modest potential to address the underlying causes of financial unsustainability. Contributing to unsustainable health care expenditures is the exponential growth in three main areas: investigative technology, surgical and medical treatments, and pharmaceutical products. Another major contributor is a free comprehensive, health care. There needs to be more patient responsibility to follow healthy lifestyles and more financial responsibility for health care premiums, drugs and received care. These payments could be made at income tax time for the previous year's services. The maximum amounts paid by patients (18 years and older) for premiums, prescribed drugs and health care would be determined as a reasonable percentage of income above the poverty line. Thus the poor don't pay and low-income families pay very little. Very fair ... very Canadian!

\section{Ross McElroy MD}

Retired family physician, Tavistock, Ont.

\section{REFERENCE}

1. Collier R. All eyes on Alberta. CMAJ 2010;182: 329 .

For the full letter, go to: www.cmaj.ca/cgi/eletters /182/4/329\#302057

DOI:10.1503/cmaj.110-2049

\section{Smart health care reform}

Re: "No more dithering on e-health: let's keep patients safe instead." Taiwan launched a nationwide Health Smart Card project in 2002 to help reduce fraud, facilitate electronic claims and improve health care quality. The 80000 authenticated card readers in the health care facilities were connected through a secure digital network to the National Health Insurance data centre. There are two versions of the card - one for citizens, one for professionals - and they are used mainly to track access to care of the insured. But they are also used to store such data as prescriptions, medical procedures, vaccinations and allergies, and are a flag for organ donation willingness. ${ }^{2}$ As a result, health care providers can use the card as a powerful tool to retain continuity of care. It is almost like a personal and portable electronic health record summary.

Min-Huei Hsu and colleagues

Taipei Medical University, Taipei, Taiwan

\section{REFERENCES}

1. McGrail K, Law M, Hébert PC. No more dithering on e-health: let's keep patients safe instead. CMAJ 2010;182:535.

2. Hsu MH, Yen JC, Chiu WT, et al. Using health smart cards to check drug allergy history: The perspective from Taiwan's experiences. J Med Syst DOI 10.1007/s10916-009-9391-5.

For the full letter, go to: $w w w . c m a j . c a / c g i / e l e t t e r s$ /cmaj.092189v1\#295561

DOI:10.1503/cmaj.110-2041 